\title{
Cultura, individualización y violencia en los metaleros de la ciudad de Lima (1994-2014)'
}

Recibido: 05/10/2016

Aprobado: 21/11/2016

\author{
Jimmy Yépez Aguirre \\ Universidad Nacional Mayor de San Marcos \\ < jimmyepez79@gmail.com >
}

\begin{abstract}
RESUMEN
Este estudio estuvo orientado a identificar las bondades que tiene el método cualitativo de la teoría fundamentada en los diferentes aspectos del sentir y pensar de los metaleros de la ciudad de Lima con la finalidad de analizar sus relaciones gregarias ante la sociedad. En tal sentido se planteó los siguientes objetivos: comprender porque se reproduce la individualización de la vida social, la mercantilización cultural y la fetichización de la música, en el sentir y pensar de los metaleros de Lima. Se hizo uso de la entrevista a profundidad, los que se aplicaron a una muestra no probabilística de 30 jóvenes y adultos metaleros (de 14 a 48 ańos, como rangos de edad o límites). Se identificó dos categorías conceptuales: la Rockandad y la Metaldad, que sirven para dar la interpretación a la problemática planteada. Por último, se elaboró un instrumento teórico conceptual llamado dialéctica piramidal para dar paso a la explicación de la investigación realizada.
\end{abstract}

Palabras clave: Individualización, mercantilización, fetichización, Rockandad, metaldad, dialéctica piramidal.

\section{Culture, individualization and violence in "heavy music" in the city of Lima (1994-2014)}

\begin{abstract}
This study was aimed at identifying the benefits that have the qualitative method of grounded theory on the different aspects of feeling and thinking of the metaleros of Lima in order to analyze their gregarious relations in society. In this regard the following objectives: Understand that reproduces the individualization of social life, cultural commodification and fetishization of music, the feelings and thoughts of the metalheads of Lima. Use of depth interview which was applied to a nonrandom sample of 30 youth and adults metalheads (14 to 48 years as age ranges or limits). The Rockandad and Metaldad, which serve to give the interpretation to the issues raised: two conceptual categories identified. And finally a conceptual theoretical instrument called pyramidal dialectic was prepared to give way to explaining the research.
\end{abstract}

KeYwords: Individualization, Comercialization, Fetishization, Rockandad, Metaldad, Pyramidal dialectic.

$1 \quad$ Los contenidos del presente artículo forman parte de la tesis: "Cultura, individualización y violencia en los metaleros de la ciudad de Lima 1994-2014" Presentada para optar el grado de Magíster en Sociología mención en Estudios Políticos en la Universidad Nacional Mayor de San Marcos. Los temas abordados se presentan con mayor amplitud en el texto de la tesis. 


\section{Introducción}

$\mathbf{L}$

a investigación de la individualización de la vida social, la mercantilización de la cultura y la fetichización de la música son temáticas centrales en el desarrollo de la sociología, por sus implicancias en las relaciones generacionales y, de manera específica, por que posibilitan una mayor comprensión al devenir de la sociedad peruana.

El propósito de la tesis es analizar el devenir de las relaciones gregarias en la reproducción de la vida social, en su construcción del habitus ${ }^{2}$ metalicus, y las estructuras políticas económicas que las contienen y reproducen, en un ida y vuelta, entre la centralidad europea/norteamericana y la periferia peruana/limeña.

Los metaleros de la ciudad de Lima, desarrollan su habitus metalicus, en una totalidad tripartita, un homo sociologicus que privilegia la individualización de la vida social, un homo economicus que privilegia la mercantilización de la cultura, y por último un homo videns, que privilegia la fetichización de la música, las absolutizaciones de los relativos; se convierten en aspectos fundamentales que definen su comportamiento presente, la edificación de una esfera privada, que genera la búsqueda de un espacio propio y del desarrollo de la individualidad, conllevan hacia la búsqueda de relaciones gregarias en la vida social, en un universal llamado Rockandad, que a la vez contiene a un particular llamado Metaldad.

\section{Problema de la investigación}

La presente investigación se propuso acercarse a la comprensión de la individualización de la vida social, la fetichización de la música y la mercantilización cultural, que a su vez generan los grandes paradigmas o tipos de expresión de libertad democrática que la juventud asume como propias en el siglo XXI, para ello se focalizó el estudio en las llamadas subculturas y en particular en el imaginario de los metaleros. Describimos y ana-

$\overline{2}$ El habitus según Bourdieu (1995: 479): "Es el principio de la estructuración social de la existencia temporal, de todas las anticipaciones y los presupuestos a través de los cuales elaboramos prácticamente el sentido del mundo, es decir su significado, pero también inseparablemente, su orientación hacia el porvenir”. Bourdieu (44) "El habitus consiste en un conjunto de relaciones históricas depositadas dentro de los cuerpos de los individuos bajo la forma de esquemas mentales y corporales de percepción, apreciación y acción”. lizamos la dinámica que generan las industrias culturales en una diversidad mundial étnica, generacional y multiculturalmente focalizadas, estructuradas social y políticamente. En un contexto de globalización continua, de consumo, de políticas culturales neoliberales, el Perú se reestructura y se cosifica a la vez en una cadena más de lo que ahora conocemos como la sociedad de consumo global.

El consumo es la parte central del moderno sistema global. Las actividades básicas de la sociedad se encuentran definidas, en gran parte, por las redes de consumo, la individualización, mercantilización, emocionalización de la cultura y la insostenibilidad de su práctica que ignora los límites biofísicos del planeta. Todos somos parte del consumo global, aunque no incluya a sectores importantes, la propia marginación es un componente intrínseco de su reproducción y establece la trayectoria de la existencia social para el conjunto de la población. Es un fenómeno heterogéneo que combina formas diferenciadas, bajo un mismo sistema de dominación, que constituye y encausa la organización social según los cánones de la modernidad tardía (Mejía, 2014: 17).

Las subculturas musicales se han hegemonizado en las principales ciudades del mundo occidental y están conquistando las nuevas ciudades emergentes asiáticas y latinoamericanas a lo largo de estos últimos 20 años, (1994-2014) para muchos investigadores la institucionalización del rock y todas sus demás variantes o subgéneros musicales han supuesto una pérdida de autenticidad, han perdido su potencial antihegemónico, siendo funcionalmente útiles para este nuevo tipo de modernidad tardía o posmodernidad, estas subculturas musicales como la de los metaleros son como la música de fondo de esta nueva era electrónica o nuevo orden mundial; germinando marginalmente en la sociedad moderna europea (en particular Inglaterra a finales de la década de los años 60), ahora gozan de un empoderamiento único.

El problema es que la oferta mediática de contracultura es hoy una oferta de mercancía. Basta ver que grupos musicales que en el tiempo de su surgimiento efectivamente resultaban ser un reto para los valores de las sociedades en las cuales surgían, hoy en día son mercancías mediáticas, caras visibles de corporaciones que planifican su marketing cuidadosamente con imágenes, textos y ritmos que son recibidos como alternos, pero es una alteridad petrificada. Los 
símbolos evocados: sexo, satanismo, deshumanización, se han convertido en "marca". La fuga local de esta forma se convierte en supeditación global a un mercado que se presenta como counterculture, pero es nada más que una modernización de un tipo de mercancía. El grupo Metallica, por ejemplo a principios del 2010 atrajo unos 50.000 espectadores en Lima, que probablemente estimaban ser parte de una counterculture en el Perú (Golte y León, 2011: $80)$.

Los metaleros de la ciudad de Lima son parte de un gran movimiento a nivel internacional que se gestó hace 48 años aproximadamente en Inglaterra, y que ahora vemos con mayor presencia en todas las principales ciudades latinoamericanas, y al interior del Perú esta subcultura musical tiene la característica de individualizar aún más la vida social de sus miembros.

Los metaleros están integrados en las principales ciudades, como una minoría presente en la sociedad de consumo de nuestro país, a través de las redes sociales virtuales, entre otros métodos. Para entenderlo de otro modo citaremos a Yúdice (2002: 297) refiriéndose a la expansión del libre comercio y el multiculturalismo:

Ya dije que el libre comercio ha adoptado el discurso de la diversidad. Y las empresas, ansiosas por legitimar su contribución a la diversidad y por expandirse a nuevos mercados, están auspiciando ex posiciones que versan sobre estos temas y como, consecuencia de ello el ethos multicultural cuenta ahora con un espacio (controvertido) en el mundo del arte hegemónico. Esto guarda coherencia con el ethos empresarial que se infiltra en todos los aspectos de la vida, aún más en el caso de la privatización promovida por el neoliberalismo.

El movimiento de estas subculturas es más comerciable y más accesible que hace 20 años atrás, donde el acceso a la música estaba centralizado en la ciudad de Lima, en lugares como la "Avenida la Colmena", "Galerías Brasil" y "Quilca", ahora la hegemonía de Internet en el modo de acceso a la música y videos, nos trae un nuevo contexto descentralizado, deslocalisado y muy comercializado y accesible para todos. "Es por esta razón que lo que Frederic Jameson (1984 citado por Gupta y Ferguson, 2008: 238) ha denominado hiperespacio posmoderno ha desafiado tan fundamentalmente la cómoda ficción de que las culturas se hallan situadas en ciertos lugares y corresponden a ciertas agrupaciones humanas".
La identidad en los metaleros es generacional y muy diferenciada, muestra una unidad o cohesión estructural muy heterogénea, cosmopolita, urbana, con rasgos conservadores y liberales, y a la vez, una contradicción que muchas veces fluye, en otras hace corto circuito, y siempre despunta una sobre la otra.

"Los jóvenes de hoy tienen facetas habituadas que comprenden cierto grado de identificación, potencialmente contradictorias entre ellas, cuyo conjunto explica la vida de una persona en el contexto social. No hay faceta verdadera o faceta falsa: cada faceta es parte integrante de nosotros, somos esas facetas" (Golte y León, 2011: 52). La imagen de los metaleros a través de los medios de comunicación de masas, como la Tv, ha sido estereotipada de una manera burlona, pintoresca, aterradora y desquiciada, haciéndolos ver como desadaptados sociales, de mente insana, con formas de vestir muy llamativas y censurables para la sociedad conservadora de las décadas de los 70 y 80 . Actualmente, esta imagen se ha asumido como natural por parte de la población mundial.

Ahora, con la aparición de los medios de comunicación de masa - que incidían de manera fuerte entre los jóvenes - no solo se daba un espacio de socialización alterna, sino una oferta continua de nuevas formas de concebir el mundo y la existencia humana que podían chocar con las ideas de las generaciones paternas. Estos conflictos podían resultar fuertes, ya que los institutos de enseñanza ofrecían espacios alternos de reafirmación no solo de una cultura generacional local, sino de hábitos diseminados por los medios de comunicación de masa, como los videojuegos, las películas, las cabinas de internet, la televisión. El escenario para un desdoblamiento de los sujetos se presentaba así.

Probablemente esta sea la razón por la cual los jóvenes - en especial aquellos socializados en los años noventa y posteriores - muestran características marcadamente diferentes de las que quienes lo antecedían. Es la generación en la cual el desarrollo de facetas alternas crece y se diversifica, y en la cual aparecen espacios de realización de facetas que no existían de la misma forma para las generaciones precedentes (Golte y León, 2011: 75 -76)

La presente investigación tuvo como objetivo desplegar muchos puntos de vistas, opiniones de los mismos metaleros, su percepción, su imaginario, ante las etiquetas, con las cuales a menudo se les asocia, como el satanismo, la violencia, la individualidad, las drogas y 
el alcoholismo. Lo que se trata es de explorar a las subculturas, el rol o la función que estas les brindan, en sus procesos de socialización de imaginarios que ellos mismos asumen, como propios, actitudes y vivencias de los jóvenes que según el $\mathrm{INEI}^{3}$, los divide: jóvenes de 15 a 29 ańos de edad y adultos jóvenes de 30 a 44 años de edad, que viene a ser el grueso de edades donde fluctúan la mayoría de metaleros.

Las características de la música, el entorno, los conflictos, sus gustos, son temas de los cuales desarrollaremos en las siguientes páginas

\section{Antecedentes}

La subcultura de los metaleros es un tema que en la actualidad cuenta con una organización llamada International Society of Metal Music Studies (ISMMS) "Sociedad Internacional para Estudios de Música Metal" fundada en el año 2010. Es una asociación dedicada al estudio de temas relacionados con el Heavy Metal y el Metal Extremo en el ámbito académico, y que busca la investigación, difusión y normalización de estos estudios.

La misión de ISMMS es fomentar y facilitar la investigación académica trans / interdisciplinarias e internacionales en relación con los procesos y fenómenos relacionados con la música heavy metal y la cultura y para apoyar el reconocimiento de este tipo de investigación como una contribución significativa a las comunidades académicas. Subgéneros del heavy metal y géneros relacionados, por ejemplo, el hardcore punk, están incluidos. ISMMS existe como una organización de coordinación para establecer estudios de música de metal como una disciplina académica relevante y respetada y contribuir al desarrollo del conocimiento dentro de las comunidades académicas y de la música. Estos objetivos se logran a través del desarrollo, la organización y la promoción de la situación de las colaboraciones de arte, publicaciones, actividades y eventos que demuestran altos estándares y principios de la excelencia académica y el objetivo importante de esta investigación en todo el mundo.(ISMMS)

$3 \quad \mathrm{Al} 30$ de junio de 2014, la población joven de Lima (de 15 a 29 ańos de edad) alcanzaría 2 millones 383 mil 30 habitantes y representarían el $27,2 \%$; en tanto, la infantil (de 0 a 14 ańos) sería de 2 millones 128 mil 509 (24,3\%). Los adultos jóvenes (30 a 44 años) llegarían a 1 millón 970 mil 381 (22,5\%), los adultos (45 a 59 ańos) concentrarían 1 millón 347 mil $905(15,4 \%)$ y los adultos mayores, es decir de 60 a más años, serían 925 mil 437 y constituirían el 10,6\% de la población limeña. (Andina)
Está conformada por músicos de metal y académicos de la cultura de Noruega, Alemania, Suiza, Reino Unido, Francia, Canadá, Nueva Zelanda, Finlandia, Brasil y Estados Unidos. Y la primera conferencia se realizó del 8 al 12 de junio en el 2015 en Helsinki capital de Finlandia.

Como se observa el estudio académico de la subcultura de los metaleros está concentrada en los idiomas de estos países, particularmente en el idioma inglés, luego el alemán y el francés, las tres grandes lenguas de la modernidad eurocéntrica y epistémicamente dominantes. Sin embargo, los estudios o investigaciones que se encuentran en la periferia como el castellano en Latinoamérica y España se presentan con muchos vacíos a modo comparativo. Podemos mencionar algunas investigaciones en Latinoamérica: la tesis en Chile de Sánchez (2007) analiza el proceso histórico de cómo llega la subcultura del metal a Chile. Luego en Colombia Maldonado et al. (2008) analizan la identidad de los metaleros.

\section{Aplicación de la teoría de Bourdieu a la música rock}

En España Pérez (2013) hace un análisis sobre la influencia y la aportación que Pierre Bourdieu hace a la sociología del rock.

Podemos adelantar, de acuerdo con (Prior 2011 citado por Pérez, M. 2013), dos usos de la obra de Bourdieu en el análisis sociológico del rock: uno, el más desarrollado hasta finales de los 90 , atiende a las dimensiones constitutivas del habitus a partir consumo cultural del rock; este uso es heredero de la lectura e impacto, básicamente, de La Distinción. El otro uso, en ascenso desde el cambio de siglo, atiende a la producción del rock como un campo cultural, y se puede rastrear su impronta en la lectura de Las Reglas del Arte, y en el mundo anglosajón en particular, en la lectura de The Field of Cultural Production. Essays on Art and Literature (recopilación de una serie de artículos que van de finales de los 60 hasta finales de los 80, y que serían la base de Las Reglas del Arte)".

Como se ve, Bourdieu está siendo revalorado y sus teorías están siendo aplicadas recientemente al campo cultural de la música rock. De acuerdo con Prior “... Bourdieu ha fijado la agenda para los estudios postmarxistas sobre las prácticas sociomusicales... sus conceptos de capital cultural, campo y hábitus han sido 
centrales para la formación de un paradigma crítico en la sociología de la música que demuestre cómo lo social produce, contextualiza o penetra en la música..." (Prior, 2011: 122 citado por Pérez, M. 2013).

Con este antecedente podemos constatar que la teoría de los campos de producción artística de Bourdieu, está teniendo una aplicabilidad en el análisis del campo de producción cultural en el rock, es un gran avance que recién se está poniendo en evidencia en estos últimos 10 años.

\section{Estudios de música metal en Perú}

En Latinoamérica y en el Perú aún no contamos con trabajos a nivel aplicativo de la sociología de Pierre Bourdieu en el campo de la sociología del rock; pero tenemos las siguientes investigaciones en Perú, especializados en el tema de la subcultura de los metaleros, tenemos el trabajo de investigación de Boggiano (1991) trabajo que está más focalizado al proceso de comunicación a través de los mensajes de las canciones de algunos bandas de música metal de Lima. Por otra parte, tenemos el artículo de Monterroso (2006) donde hace un análisis del discurso de la música metal girando en los ejes del placer y la muerte de manera general y buscando resaltar una autenticidad existencial y a la vez de aspectos simbólicos que cubren el ropaje de la música metal. También tenemos el artículo de la tesis de Yépez, (2013) en el cual se hace un análisis entre la relación de la política cultural neoliberal y la música Heavy Metal en la ciudad de Huánuco. Y por último un artículo de Yrivarren (2015) donde se desarrolla de manera descriptiva el ambiente y las características que tienen los metaleros de la ciudad de Lima, mostrándonos la esencia del lugar de los metaleros a la cual la autora llama "el genius loci".

La subcultura de los metaleros en Perú se percibe en el campo de la investigación prácticamente como un tema exploratorio y de conocedores, que aun así podemos contar con escasas investigaciones, tesis, monografías, artículos o notas locales. Después tenemos investigaciones más genéricas y abarcativas no focalizadas o especializadas en temas como la subcultura de los metaleros, sino más históricas y descriptivas que nos hablan del rock local y sus diferentes ramas o subestilos, donde se mencionan a los metaleros, entre las más recientes publicaciones en Lima tenemos la de Yrrivarren (2012), donde hace un mayor énfasis en el aporte urbanístico que pueden dar las tribus urbanas, y al comercio segmentado especializado de lo cual es característico de las tribus urbanas. También tenemos los trabajos de Torres (2012). Donde se hace un recuento histórico de la década de los años 80. Otro autor con más publicaciones al respecto en lo referente a la historia y el proceso descriptivo de rock peruano es Cornejo (2002). Este es uno de los cuatro libros que tiene donde desarrolla el tema de la música rock peruana. Como se puede apreciar a groso modo nuestros autores no profundizan ni desarrollan la temática de la fetichización de la música y la individualización de la vida social como violencia simbólica en las subculturas de los metaleros de la ciudad de Lima. Esto nos motivó a indagar y a investigar para contribuir a conocer más las realidades de las subculturas en este caso particular la de los metaleros de Lima, que son parte de esta nueva estructura social peruana que nos hace parte del capitalismo global de consumo.

\section{Método \\ Tipo de investigación:}

La investigación es de carácter exploratorio, descriptivo e interpretativo. Exploratorio porque examina un tema poco estudiado y descriptivo porque su propósito es describir la reproducción de la individualización, la mercantilización y la fetichización en el imaginario de los metaleros. Interpretativo porque sistematiza y explica la articulación de los ciclos y procesos del mercado - individuo - fetiche:

Homo - Habitus - Imaginarius.

\section{Participantes:}

Se tomó una muestra no probabilística intencional o selectivo de 30 personas lo que permitirá garantizar el punto de saturación $n^{4}$ para lograr la representatividad científica de la población, dada las características espe-

$4 \quad$ El punto de saturación del conocimiento es el examen sucesivo de casos que va cubriendo las relaciones del objeto social, de tal forma que a partir de una cantidad determinada los nuevos casos tienden a repetir — saturar - el contenido del conocimiento anterior (...) El punto de saturación es un proceso que supone, por un lado, la diversificación al máximo de los casos de estudio, que dan cuenta de los diferentes niveles que muestra la heterogeneidad estructural del objeto de estudio. Se requiere que todos los niveles estructurales de la heterogeneidad del universo se encuentren representados por las unidades de la muestra (...) Como resultado de la experiencia práctica de investigación, Betraux establece alrededor de 30 el número de casos necesarios para lograr el punto de saturación (Mejía, 2002: 125-126). 
ciales de la unidad de análisis, se tomara en cuenta lo siguiente:

a) Características socioestructurales

$\checkmark$ La ciudad de Lima:

$\checkmark$ Hábitat

$\checkmark$ Espacios de encuentro

$\checkmark$ Rango de edades

$\checkmark$ Sexo

b) Tamaño de la muestra: $\checkmark \quad$ Número de unidades de análisis 02:

$\checkmark$ Metaleros varones (15) [5 Negociantes - 5 Músicos - 5 Fanáticos]

$\checkmark$ Metaleras mujeres (15) [5 Negociantes - 5 Músicos -5 Fanáticos] $\checkmark$ Total de casos: 30

c) Panel de representación de cinco generaciones de metaleros:

\begin{tabular}{|c|c|}
\hline HOMO ECONOMICUS METALICUS VARONES & HOMO ECONOMICUS METALICUS MUJERES \\
\hline 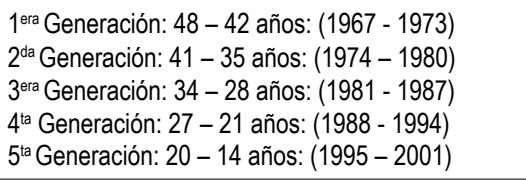 & 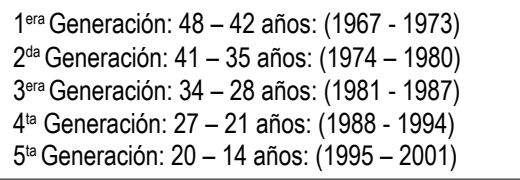 \\
\hline HOMO SOCIOLOGICUS METALICUS VARONES & HOMO SOCIOLOGICUS METALICUS MUJERES \\
\hline 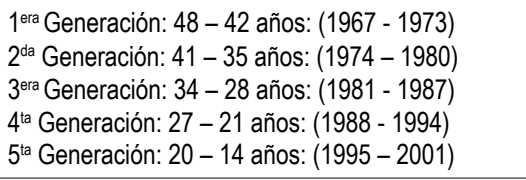 & 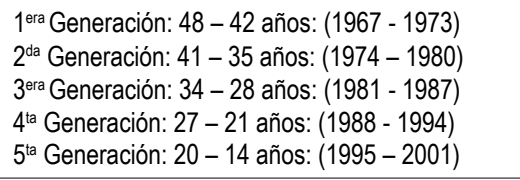 \\
\hline HOMO VIDENS METALICUS VARONES & HOMO VIDENS METALICUS MUJERES \\
\hline 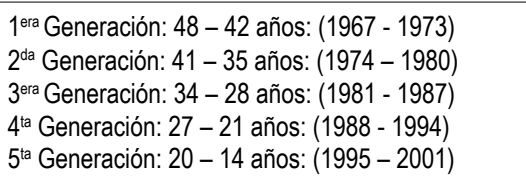 & 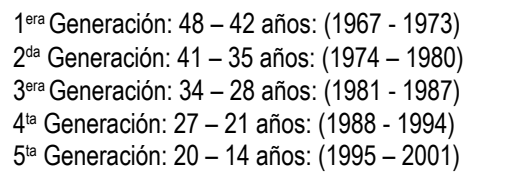 \\
\hline
\end{tabular}

Fuente: elaboración propia.

d) Panel de representación socioestructurales: Representación de la matriz

\begin{tabular}{|c|c|c|c|c|c|c|c|}
\hline Hábitat & Espacios de encuentro & Categorías & $\begin{array}{l}\text { Actores involucrados en } \\
\text { la escena Metal }\end{array}$ & Rango de edades & $\begin{array}{l}\text { Generaciones } \\
(1967-2001)\end{array}$ & Sexo & $\begin{array}{l}\text { Unidad } \\
\text { personas }\end{array}$ \\
\hline \multirow{27}{*}{ Lima } & \multirow{9}{*}{$\begin{array}{l}\text { Galerías } \\
\text { Bares } \\
\text { Conciertos } \\
\text { Parques } \\
\text { Ferias } \\
\text { Salas de ensayo }\end{array}$} & \multirow{9}{*}{$\begin{array}{l}\text { Homo Sociologicus } \\
\text { Metalicus }\end{array}$} & \multirow{9}{*}{$\begin{array}{l}\text { Imaginarius Ideograficus } \\
\text { \& Músicus. }\end{array}$} & \multirow{2}{*}{$48-42$} & \multirow{2}{*}{ Primera } & $\mathrm{M}$ & 1 \\
\hline & & & & & & $F$ & 2 \\
\hline & & & & \multirow{2}{*}{$41-35$} & \multirow{2}{*}{ Segunda } & M & 3 \\
\hline & & & & & & $\mathrm{F}$ & 4 \\
\hline & & & & \multirow{2}{*}{$34-28$} & \multirow{2}{*}{ Tercera } & $\mathrm{M}$ & 5 \\
\hline & & & & & & $\mathrm{F}$ & 6 \\
\hline & & & & $27-21$ & Cuarta & $\frac{M}{F}$ & $\frac{7}{8}$ \\
\hline & & & & \multirow{2}{*}{$20-14$} & \multirow{2}{*}{ Quinta } & $\mathrm{M}$ & 9 \\
\hline & & & & & & $\mathrm{F}$ & 10 \\
\hline & \multirow{9}{*}{$\begin{array}{l}\text { Galerías } \\
\text { Bares } \\
\text { Conciertos } \\
\text { Parques } \\
\text { Ferias } \\
\text { Salas de ensayo }\end{array}$} & \multirow{8}{*}{$\begin{array}{l}\text { Homo Economicus } \\
\text { Metalicus }\end{array}$} & \multirow{9}{*}{$\begin{array}{l}\text { Fanaticus, Commercium } \\
\text { \& Militancia }\end{array}$} & \multirow[t]{2}{*}{$48-42$} & \multirow{2}{*}{ Primera } & $\mathrm{M}$ & 11 \\
\hline & & & & & & $\mathrm{F}$ & 12 \\
\hline & & & & $41-35$ & Segunda & $\frac{M}{F}$ & $\frac{13}{14}$ \\
\hline & & & & \multirow{2}{*}{$34-28$} & \multirow{2}{*}{ Tercera } & $\mathrm{M}$ & 15 \\
\hline & & & & & & $\mathrm{F}$ & 16 \\
\hline & & & & \multirow{2}{*}{$27-21$} & \multirow{2}{*}{ Cuarta } & M & 17 \\
\hline & & & & & & $\mathrm{F}$ & 18 \\
\hline & & & & \multirow{2}{*}{$20-14$} & \multirow{2}{*}{ Quinta } & M & 19 \\
\hline & & \multirow{10}{*}{$\begin{array}{l}\text { Homo Videns } \\
\text { Metalicus }\end{array}$} & & & & $\mathrm{F}$ & 20 \\
\hline & \multirow{9}{*}{$\begin{array}{l}\text { Galerías } \\
\text { Bares } \\
\text { Conciertos } \\
\text { Parques } \\
\text { Ferias } \\
\text { Salas de ensayo }\end{array}$} & & \multirow{9}{*}{$\begin{array}{l}\text { Violencia Imaginaria \& } \\
\text { Violencia Mediática. }\end{array}$} & $48-42$ & Primera & $\frac{M}{F}$ & 21 \\
\hline & & & & & & $M$ & 23 \\
\hline & & & & $41-35$ & Segunda & $\mathrm{F}$ & 24 \\
\hline & & & & $34-28$ & Tercera & M & 25 \\
\hline & & & & & TeICEId & $\mathrm{F}$ & 26 \\
\hline & & & & $27-21$ & Cuarta & $\mathrm{M}$ & 27 \\
\hline & & & & & & $\frac{F}{M}$ & 28 \\
\hline & & & & $20-14$ & Quinta & $\frac{M I}{F}$ & 29 \\
\hline & & & & & & & reinta \\
\hline
\end{tabular}

Fuente: elaboración propia. 
Instrumentos:

Guía de entrevista a profundidad y la dialéctica piramidal $^{5}$

\section{Resultados: Análisis descriptivos sintéticos}

\section{Industria cultural metalera en Lima:}

1.1 Matriz de las artes escénicas. Enunciado descriptivo sintético

1.1.2 Caracteristicas y expresiones de los metaleros en las artes escénicas: música-danza-teatro

La energía, intensidad y pasión que la música metal caracteriza se ve expresado corporalmente en el Headbanging o mosh (movimiento de cabeza) y el pogo (baile de empujones) que se retroalimenta con la actitud y puesta en escena que los grupos metaleros despliegan en sus actuaciones en vivo.

Un mundo paralelo y quizás alternativo a lo hegemónico y convencional como las discotecas y el baile como cortejo que viene a representar en el imaginario de los metaleros, ellos optan y sienten las otras posibilidades de expresiones que la música metal les ofrece, son consientes del rechazo y la intolerancia e incomprensión que ocasionan a su pares contemporáneos, sus espacios, sus sonidos y expresiones que brinda la música metal para ellos, les hace aun más atrayentes y consolida su personalidad individualizada. Que tiene mucho acercamiento con temas históricos, medievales, paganos, ocultistas, guerras y hasta con términos médicos que los grupos metaleros desarrollan en su propuestas de letras, o la simple melodía virtuosa, sean más que suficientes razones para tener adeptos a este estilo musical el metal. "Así como la sociedad de la Edad media encontraba su equilibrio apoyándose en Dios y en el Diablo, la nuestra se equilibra buscando apoyo en el consumo y su denuncia" (Braudillard, J. [1979] (2009: XIV) .

5 Dialéctica piramidal: Es un constructo "tipo ideal" construido para el mejor entendimiento del desarrollo de la música y su relación con las estructuras políticas, púes no existe como tal. Bauman Z. (2007: 45) "Max Weber lo llamó "tipos ideales": abstracciones que intentan captar la singularidad de una configuración compuesta". Se puede usar como herramienta como una configuración compuesta que permita la descripción de una realidad social empírica o en la explicación y desarrollo de estudios de investigación.

\subsection{Matriz de los audiovisuales: Medios de comunicación e individualización del metalero 1.2.1 Enunciados descriptivo sintético: cine-Tv-radio- internet-videojuego}

Los medios de comunicación masivos desarrollan en muchos casos estrategias de filtro y reorientan a los grupos de música metal a ciertos estándares según el género de música metal. La facilidad, el acceso, muestra sus bondades con internet, instrumento para muchos, como una herramienta útil en el aprendizaje de todo tipo de interés. La otra cara de esta nueva facilidad virtual, es la mayor individualización del sujeto, hasta cierto aislamiento con otros metaleros, o una menor interrelación física presencial. La $\mathrm{Tv}$ por su parte los toma de manera pintoresca y hasta en cierto modo sensacionalista. Prejuicios, que se vuelven filtros en los demás medios informativos de masas, como la radio en señal abierta donde la ausencia de programas de música metal, se manifiesta plenamente, quizás por carencia de propuestas, quizá por imposición. Los documentales sobre la música metal son apreciados pero no muy conocido por todos los metaleros, las películas que más gustan los metaleros son de tramas, épicas, de ciencia ficción. La música metal es también utilizada en muchos videos juegos, y los metaleros también forman parte de ese grupo consumidor, muchos de ellos tuvieron su etapa de vicioso, y otros simplemente los jugaron, sin mayor ahincó. En concreto la industria de la música metal siempre estuvo presente y en los últimos 20 años la han tomado en cuenta, sobre todo más en el mundo internacional. El Perú las condiciones de difusión de este género musical ha sido muy poca, teniendo programas como el recordado "Viernes de Metal" (1991) en canal 7, o programas de radio como "Heavy Metal para escolares" (1987) en radio doble nueve. Son algunos de los programas que los metaleros más antiguos de Lima recuerdan.

\subsection{Matriz de la literatura y publicaciones: La modernidad en la lectura o el desinterés de la lectura \\ 1.3.1 Hábitos y conocimientos de la literatura y publicaciones Enunciados descriptivos sintéticos: libro- prensa-revistas}

Las publicaciones de libros sobre la música metal de manera internacional es regular, la carencia de publicaciones de libros de música metal en el Perú, si es 
muy precaria, por no decir inexistente. Los hábitos de lectura de los metaleros son variados, según el interés, la costumbre, la formación ocupacional y profesional que cada uno posee influirá en su decisión. La prensa, los periódicos dan cierta información de eventos internacionales, algunos pequeños artículos periodísticos, algunas revistas y fanzines que salen esporádicamente. Que la verdad tienen muy pocos seguidores, por el efecto internet, que ha tomado el control total del acceso a la información, toda consulta es vía internet, todo pequeńa lectura es leída mediante este formato virtual, la informática está absorbiendo a la industria del libro y las revistas.

Facilidad, acceso, rapidez, compiten con formatos más tradicionales, que las nuevas generaciones están dejando de lado. La tres pantallas, la primera el Tv, la segunda la computadora y la tercera el celular; la triada perfecta que explica el ciclo de desarrollo audiovisual, en el cual estamos. La tesis (tv) - la antítesis (internet) - la síntesis (el celular). Lo portátil, la individualidad como signo de distinción y personalidad ante la sociedad de consumo. "Emplear la expresión cultura de consumo es subrayar que el mundo de los bienes y sus principios de estructuración son fundamentales para comprehender la sociedad contemporánea" (Featherstone, M. 1991:144) Por otra parte se podría complementar el análisis de Roberto Igarza que nos dice: "Los contenidos audiovisuales son centrales en el nuevo ecosistema cultural masivo de consumo individual... La sociedad del ocio intersticial representa un verdadero desafío para la cultura” (Igarza, 2009:13)

\section{Habitus Metalicus: Musicus \& Fanaticus}

\subsection{Matriz antropológica metalera:}

\subsubsection{Una mirada antropológica hacia los metaleros.}

Enunciados descriptivos sintéticos antropológicos: costumbre-lengua-tiempo-espacio-simbología-fanatismo

Las costumbres más percibidas mucho tienen que ver con la idiosincrasia del país en sí que es el tomar en reuniones, ocasiones especiales, y eso es un concierto de música metal, porque no es algo de todos los fines de semana al ańo, es un momento una ocasión en el cual se puede compartir de la manera más tradicional que es el tomar, las aficiones en particular será un componente fundamental para la mayor cohesión a los grupos y empatías entre los mismos metaleros diversificados por los gustos y estilos, que no a todos les gusta por igual, siempre unos prefieren sus particularidades, su sentir.
El ser aficionados a los carros, quizás sea motivo extra para compartir aún más sus vivencias, a parte del gusto de la música, y así por el estilo, se refuerzan y se hacen amistades más estables y duraderas, hasta que un mal negocio, o un problema de faldas los separe, suele pasar, a menudo sobre todo en este último.

Los valores tienen mucho que ver al respecto, el sentimiento de pertenencia de identidad juega un papel decisivo, que se refleja en la emoción que ellos sienten al ver un producto relacionado a la subcultura metal, sus símbolos e imágenes, de pentagramas, calaveras, muerte, lo misterioso, lo prohibido, es el caudal en el que la música metal se nutre y se diversifica. El idioma queda para muchos a un segundo plano, lo primero es la melodía, el sonido, la música. La propuesta temática es algo que se adquiere con la madures del sujeto, con el conocimiento, la educación autodidacta que el metalero se pueda inculcar, eso quiere decir, que no todos hacen ese proceso, de entender la propuesta, que sería algo más completo, que el simplemente llevarse por el sonido.

El estilo de vida que la música les puede ofrecer, no es compartido y aceptado por todos, hay que diferenciar en aquellos que les gusta la música metal, y otros que se identifican como metaleros, hay mucha diferencia, a simple vista quizás pase desapercibido, pero con mayor detenimiento y atención uno puede diferenciar muy fácilmente, el pez muere por la boca y en muchos casos por la actitud.

Sin embargo, también podemos hablar de fugas individuales ante las imposiciones y discursos que homogenizan a las personas en comportamientos y gustos ligados a la sociedad de consumo por un lado, y el control de la conducta por otro. Estas fugas individuales constituyen un tipo de fuga activa que se genera por la oposición a ciertas situaciones o condiciones propias del entorno del sujeto que se desenvuelve, por ejemplo, en espacios con grandes restricciones. Ello se expresa en la búsqueda de espacios alternos de socialización que son conocidos como alternativos o contraculturales, ligados también a un consumo cultura pero de menor alcance. Dichos espacios alternos se constituyen no solo como espacios de escape al mundo consumista que se puede presentar homogeneizante, sino también a las normativas familiares, escolares, sociales, etc. De la sociedad mayor o, en otros términos, del sistema al que parte de los jóvenes suele mostrarse contestataria en distinta medida (Golte, 2011: 77). 
2.2 Matriz sociológica metalera:

2.2.1 Una mirada de los metaleros desde la sociología. Enunciados descriptivos sintéticos: clase socialsociodemográfico-socioeconómico-sociopolítico-estatus social

Los metaleros no se libran de la discriminación y el prejuicio social que entre ellos mismo se reproducen, territorialismo, separación a los otros, bichos, que se huelen y se diferencia, tratándose de superior - iguales o inferiores ¿herencia colonial? Los estilos de vida son diferenciados sus ocupaciones y profesiones, no están vinculados a sus gustos musicales necesariamente, se encuentra de todo. La libertad de expresión es un beneficio intrínseco del genero, es la ventaja de no ser muy comercial, te da más libertad de expresarte, pero ya hay ciertos indicadores que hasta se podría cuestionar aquellas libertades, que muestran un patrón repetitivo, un forzar a hablar de ciertos ejes temáticos, que en los últimos 40 años se han hecho demasiado notorios, y por ende nada novedosos. Siempre es bueno romper la regla. El beneficio es sin duda el cultural y social que el género te incita a averiguar a investigar, en lo económico solamente para algunos comerciantes y pocos grupos locales, pero la tendencia es más una satisfacción interna personal.

\section{Imaginarius Metalicus \& Doxa Mediatica:}

3.1 Matriz tipos de violencia mediática: violencia grupal - violencia individual

3.1.1 Violencia mediática o estereotipos hacia los metaleros. Enunciados descriptivos sintéticos de tipos de violencia mediática: pelea-físicas-sicológicas-sexuales

La violencia grupal en los metaleros es una violencia prefabricada, por los medios de comunicación a través de sus películas, crean una imagen que no concuerda con los seguidores de este estilo musical, quizás la violencia grupal, en pocas ocasiones se hace notar, en el contexto de la zona por lo general, en los conos de Lima, otro factor es la personalidad relacionada al entorno, el problema con el alcoholismo, la drogadicción, problemas que no todos los metaleros padecen, el comportamiento grupal, el dejarse llevar, es otro factor que influye, en las pocas ocasiones que se animan hacer algo, que por lo general no pasa de hacer un pogo (baile de empujones) eufóricamente entre metaleros. Aunque siempre hay algún desadaptado que mete su puñete y su patada.
No hay carácter que los defina, son variados y extremos de muy tranquilos hasta muy endemoniados. La pornografía a la mayoría les agrada, pero a otros la repudian, piensan no ser tan fetichistas, les gusta más la práctica, el acto en sí. Otros ambas cosas a la vez, en el tema de la orgia, los metaleros de lima son conservadores, tienen cierto rechazo de ser vistos en el acto sexual por otro hombre, les causa molestia, para otros es cuestión de ánimos.

Y la prostitución para los metaleros es algo natural que la sociedad debe tener, un mal necesario que alguien tiene que cumplir, una cierta lógica funcional, es la que maquina en algunos cerebros de los metaleros, pero también hay quienes son conscientes, que detrás de eso, muchas veces hay el forzamiento, el negocio, la trata de blancas, es lo que rechazan y condenan como malo, y otros son indiferentes, de solamente ver un servicio ofrecido, que lo único que consideran es la salubridad de ambos.

\subsection{Matriz de tipos de violencia imaginaria: Hiperreal y Simbólica.}

3.2.1 Enunciados descriptivos sintéticos de tipos de violencia imaginaria: Headbanging \& pogo-dominación masculina-subalternización colonial-tradiciones antiguas de trance emocional

El Headbanging o Mosh no es simulación de violencia para los metaleros, es para ellos liberación, expresión que es controlada. La sensación que produce en ellos es como un frenesí, es placer al máximo. Y la manera como se complementa al pogo, no es arbitraria, es voluntaria, ya que son independientes el uno del otro, el Headbanging o mosh es la expresión de la individualidad y el pogo el de la colectividad. El origen de estos actos los desconocen totalmente, salvo excepciones que hacen más mención sobre el pogo, como bailes o expresiones africanas, indias, y hasta selváticas, como posibles ancestros de dicha expresión corporal como es el pogo.

El metal femenino es bienvenido, aunque en ciertos cerebros aun quedan prejuicios machistas, donde ninguna mujer puede tocar mejor que un hombre o saber más de música que uno. La estética, es lo que más aprecian los metaleros en las mujeres, más que en como tocan, o su calidad artística interpretativa, las voces femeninas en géneros musicales como el Black y el Death Metal, tiene mucha acogida. Pero siempre mencionan que aún no aparece un buen grupo de música metal en Lima. Lo subalterno, es algo que muchos no consideran, piensan que hay las mismas oportunidades 
para todos, aunque son conscientes que las mujeres de música metal, son más convocadas, para los conciertos que cualquier otro grupo de jóvenes.

La cultura andina amazónica, tiene mayor aceptación en los últimos tiempos, y también las personas de rasgos andino-amazónicos, pero también persiste el prejuicio, el racismo hacia los otros. El limeño es cerrado es exquisito, mientras que el provinciano es abierto con mayor predisposición a la novedad, al intercambio, quizás por eso el poner música metal en una comunidad campesina tuviera éxito, pero siempre manteniendo sus costumbres, fiel a ellas, mantendrían otra subcultura, como la de los metaleros.

\subsection{Matriz de la Doxa Metalica (Habitus \& Imaginarius)}

3.3.1 Enunciados descriptivos sintéticos de la Doxa Metalica (Habitus \& Imaginarius): argumentos-aportesvivencias

La música metal está compuesta por elementos que lo hacen único en su género, vivencias y planes a futuro, son una constante para muchos, para otros es el momento la diversión, el placer que la misma música les ofrece. Para otros es una fuente de conocimientos de temas muchas veces vetados, ocultos, históricos, de saberes ancestrales, invisibilizados por el orden y la cultura dominante, para otros les da temas de conversación e investigación.

\section{Resultados: Análisis interpretativos}

\section{Ciclos de la Política-Industria-Habitus-Imaginarius: 4.1 Periodos de la industria cultural según la dialéctica piramidal:}

Para periodizar nos remontaremos a dos hechos históricos institucionales que es la fundación del GATT 1948 (Acuerdo General sobre las Tarifas Aduaneras y el Comercio), y la Organización Mundial del Comercio en 1994 (OMC). Según nos dice (Warnier, 1999: 83)

Las organizaciones comerciales (el GATT y luego la $\mathrm{OMC}$ ) deben pues cumplir una función; pues la cuestión es vital: se trata de establecer las reglas de juego de los intercambios mundiales en el ámbito global. El problema por resolver es el siguiente: ¿Cómo establecer reglamentaciones universales, acuerdos multilaterales y alineamiento de tarifas y de barreras aduaneras sin poner al débil a merced de del fuerte? (...) Puesto que los productos de las industrias culturales son objeto de un comercio, caen en la esfera de competencia del GATT o de la OMC.

Estos referentes marcan muy notoriamente los dos nuevos procesos que se enmarcan a las nuevas producciones musicales y culturales del mundo de posguerra hasta la actualidad, es en este contexto histórico donde se desarrollara el tema de la investigación, que comprende el segundo periodo histórico que tiene como referente a la OMC (1994). Entonces tenemos dos periodos claramente marcados: primero el GATT (19481993) es un sistema de reglas fijadas por naciones; mientras que la OMC (1994-hasta la actualidad) es un organismo internacional multilateral. Esto se puede apreciar panorámicamente en el horizonte histórico de sentido cultural que permite a la dialéctica piramidal estructurarla del siguiente modo:

Primer horizonte histórico de sentido de la dialéctica piramidal (1945-1993)

Apreciación: Como se observa en la dialéctica piramidal, parte del año 1945, como punto inicial de una nueva geopolítica internacional, nuevo poder hegemónico cultural liderado por EE.UU. y enfrentado a la URSS. Desde 1948 entra en vigencia el GATT, en esos años también se hegemonizan las ideas políticas del Estado del bienestar keynesiano, su negación de esta política sería "la creación de la sociedad Mont Pélerin, una suerte de francmasonería neoliberal que fue fundado en 1947" (Anderson, 2003: 26) como una reacción teórica y política vehemente contra el Estado intervencionista y del bienestar keynesiano. En este trasfondo político-económico es donde se desarrollará la primera oleada de las industrias culturales la consolidación de la TV, la masificación de la radio, la popularidad de los cines, el despegue de la música pop y la cultura de masas, que tendrá su auge en la bipolaridad de la guerra fría. En un proceso dialéctico donde la matrix de este periodo fue sin duda la música rock como partera de los diferentes estilos musicales que hoy conocemos.

Segundo horizonte histórico de sentido de la dialéctica piramidal (1994-2042)

Apreciación: En este segundo ciclo de la dialéctica piramidal, parte de la primera crisis financiera en México del año 1994, como ícono de un establecimiento neoliberal a nivel mundial, porque luego vendrían 
GRÁFICO 1

PRIMER HORIZONTE HISTÓRICO DE SENTIDO DE LA DIALÉCTICA PIRAMIDAL (1945-1993)

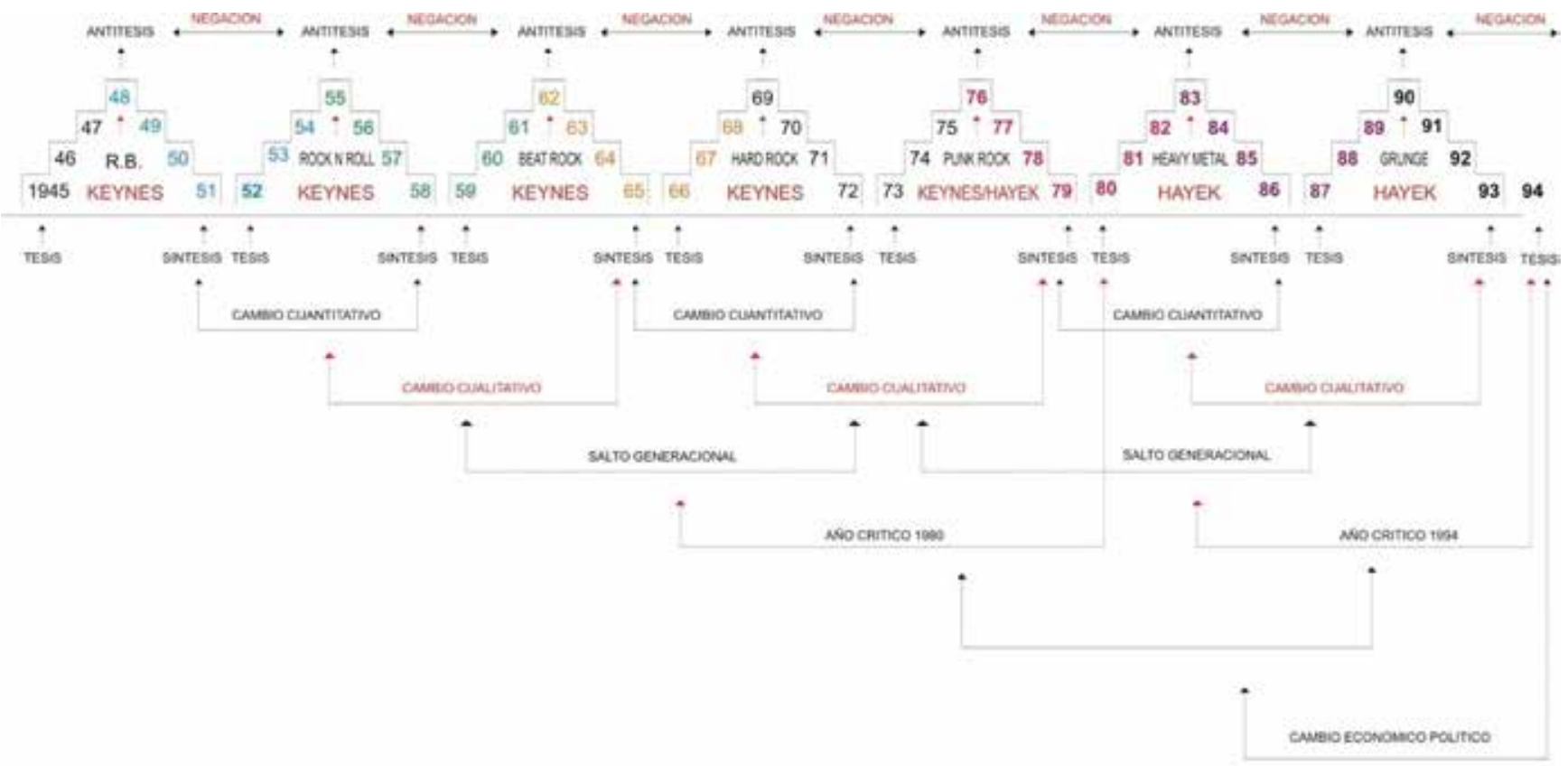

Fuente: Elaboración propia.

\section{GRÁFICO 2}

SEGUNDO HORIZONTE HISTÓRICO DE SENTIDO DE LA DIALÉCTICA PIRAMIDAL (1994-2042)

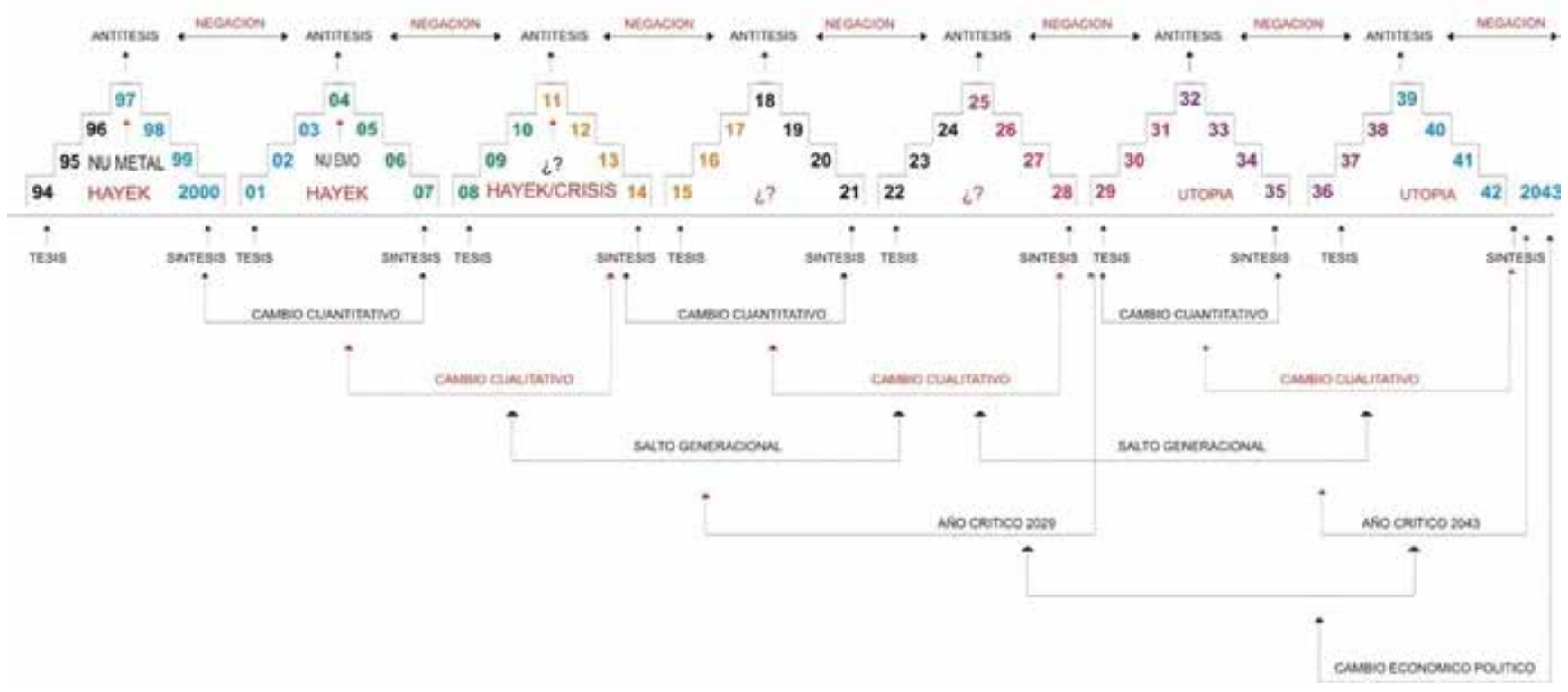

Fuente: Elaboración propia. 
más crisis financieras como los años 1997, 1998, crisis asiáticas, rusas, brasileña. Este fenómeno de las crisis financieras a nivel mundial es característico de esta nueva etapa de la globalización neoliberal, que trae la continuidad del GATT, pero reformado como OMC, en 1994, como claro signo del poder global en un contexto globalizado. Empoderado por las nuevas industrias creativas las redes virtuales de internet serán los nuevos instrumentos de poder con la telefonía celular de hegemonizar la colonización de las nuevas subjetividades de las nuevas generaciones.

La fuga al universo mediático es por cierto más fácil en una sociedad que reproduce hábitos de exclusión en una competencia extraordinaria por ocupar sitios en la distribución de la riqueza. Así que encontramos como consecuencia una adicción a lo inmediato y la falta de una perspectiva temporal en la superación de la situación que condujo al individuo a la fuga. En situaciones extremas, en las cuales los antepasados de los jóvenes de hoy pensaban y planificaban vías de acceso a mejores niveles de bienestar, encontramos casi una mayoría de descendientes que ha renunciado a una perspectiva temporal en su acción. Las aspiraciones son encapsuladas en una realización mediática virtual que no se ubica en el tiempo real (Golte y León, 2011: 79)

En lo musical la mezcla como esencia será fundamental; tenemos como un género representativo a la música NU METAL, que es una mezcla entre la música rap y el metal, este pequeño ejemplo se ve diversificado en los diferentes estilos que conlleva la década, es época del multiculturalismo, de las pequeñas exaltaciones, de lo particular, de las minorías, de las identidades locales, de lo subalterno, de lo alternativo; es tiempo de deconstruir la idea del Estado-nación, del GATT, cambiar por la OMC es el auge del pensamiento posmoderno. Acá parte la nueva matriz Heavy Metal, como piso o música de fondo para el nuevo orden mundial, que al igual que la música rock fue absorbido por el establishment. Heavy Metal, la nueva partera de las siguientes fusiones de sonidos distorsionados y amplificados característicos de esta nueva modernidad tardía; experimentaciones musicales de la globalización cultural.

En palabras de Yudice y Miller:

La UNESCO, el GATT/OMC y estos bloques regionales ofrecen diferentes perspectivas sobre la expansión neoliberal en la cultura y sobre la globalización de las mercancías textuales. Oscilan entre los modelos de libre mercado, que ayudan a los bloques de poder existentes, el proteccionismo cultural, que crítica la dominación política y económica, y las agrupaciones continentales de la industria cultural, que se remiten a los debates sobre el ciudadanoconsumidor, contraponiendo el placer de elegir a la fidelidad a la nación y a las tradiciones, pero que procuran sortear las complicaciones concomitantes privilegiando la producción local, cuando ello es factible. Estados Unidos, el mercado cultural más cerrado en la historia del mundo, lo hace valiéndose del poder de las grandes empresas. (2002:247)

La expansión mercantilista en la cultura tiene sus puntos de partida primero en el GATT, creado en 1948, como una primera etapa más tradicional en política económica y en rentabilidad cultural hasta 1993, que da fin a un ciclo expansionista y de penetración de los medios de comunicación masivos, para entrar a un nuevo ciclo $\mathrm{u}$ horizonte histórico de sentido cultural hegemonizando lo subalterno, las minorías, las subculturas, todo lo alternativo, y creativo del primer ciclo u horizonte histórico de sentido cultural que se desarrolló (1945-1993). Ahora en el nuevo ciclo u horizonte histórico de sentido cultural que empieza en 1994, todas esas corrientes son parte del mundo académico contemporáneo, publicitado y hasta mercantilizado hasta la saciedad, todo es vendido, todo es marketeado, entramos en un nuevo proceso interno de contradicciones, de nuevas generaciones, de nuevas contribuciones. Lipovetsky y Serroy (2009: 279) lo caracterizan así:

Ironía de nuestra época. Cuanto más inmaterial y virtual se vuelve nuestro mundo, más se extiende una cultura que valora la sensualización, la erotización, la hedonización de la existencia (...) La cultura de la pantalla se consolida al mismo tiempo que la artistificación de los estilos de vida y la hedonización del consumo.

\section{Conclusiones}

Comprender porque se reproduce la individualización de la vida social, es comprender el envenenamiento, que la mercantilización hace a la cultura y como esta a su vez fetichiza las relaciones sociales, volviéndolas gregarias, absolutizando lo relativo, la pulsión de muerte y la pulsión del eros se vuelven una totalidad.

La rockandad es el proceso universal que enmarca y contextualiza el devenir de la individualización de la 
vida social. La rockandad es el logos del mercado. La metaldad es la particularización que se desprende, para formar su propio universal. La metaldad es el mito del mercado

La rockandad es la cristiandad laica; la metaldad es el protestantismo inverso pagano.

El capital simbólico de la metaldad es la visibilización de lo que la sociedad invisibiliza.

La violencia de los metaleros es mítica, simbólica. Su simbología te inicia a dos mundos, uno fenomenológico (estético, de placer y consumo) y otro noumenico, (de conocimiento, de entendimiento, de creación).

Los tipos de individualización dependen del tipo de envenenamiento que el sujeto ha experimentado en su infancia, su niñez y su adolescencia.

La naturalización de la individualización de la vida social del metalero de Lima se debe a su fijación en la identidad, de ser reconocido, es la otredad, lo que lo empuja a desmarcarse de sus pares.

Si los rockeros quieren vivir en las utopías, el metalero quiere vivir en las distopías. El metalero es un proceso del mercado, es un puente que tiene que ser superado. Porque él está limitado a su finitud, a su ruido, y todo ruido tiene un devenir político y toda política está destinada a cambiar de piel y de música.

\section{Categorización:}

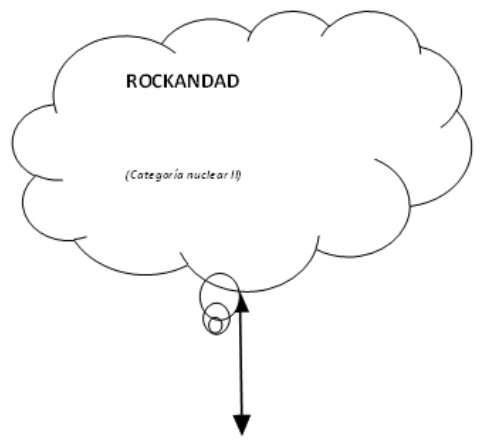

RELACIONES GREGARIAS

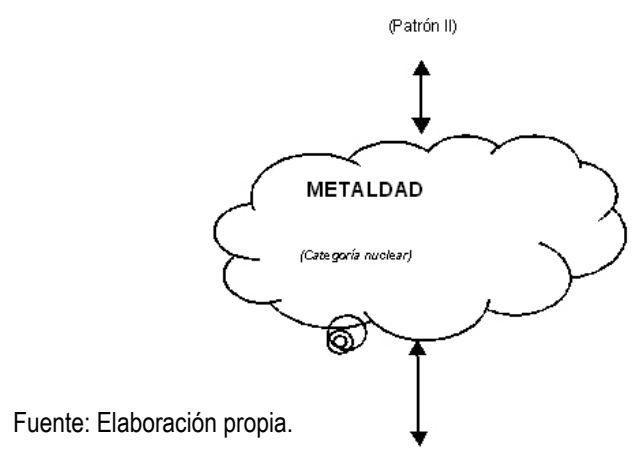

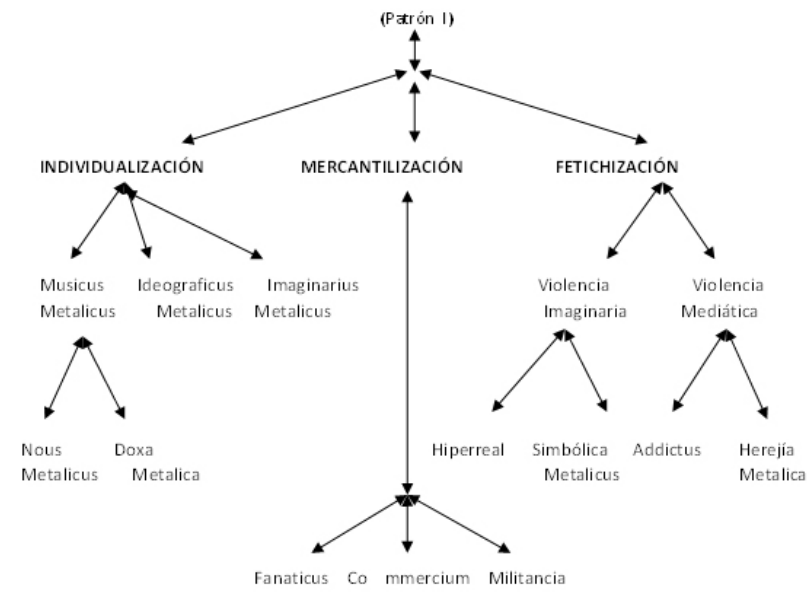

HABITUS METALICUS

Fuente: Elaboración propia

\section{Referencias bibliográficas}

Anderson, P. (1999). Neoliberalismo: un balance provisorio. En: Sader E. \& Gentili P. (Compiladores) La trama del neoliberalismo. Mercado, crisis y exclusión social. Argentina: CLACSO - EUDEBA Editora Universitaria de Buenos Aires pp. 25 -38.

Baudrillard, J. (2009 [1970]). La sociedad de consumo. Sus mitos, sus estructuras. Madrid: Siglo XXI de España Editores S.A

Bauman Z. (2007) Vida de consumo. México: fondo de cultura económica.

Boggiano, L. (1991). Primera aproximación al fenómeno musical: Heavy Metal, análisis de su contenido y mensaje. (Trabajo de investigación). Lima: Pontificia Universidad Católica del Perú.

Bourdieu, P. \& WacQuant L. (2005). Una invitación a la sociología reflexiva. Buenos Aires: Siglo XXI Editores, S.A.

Bourdieu, P. (1995). Las reglas del arte. Génesis y estructura del campo literario. Barcelona: Editorial Anagrama.

Cornejo P. (2002) Alta tensión: los cortocircuitos del rock peruano. Lima: Emedece Ediciones.

Featherstone, M. (1991). Cultura de consumo y posmodernismo. Argentina: Amorrortu Editores.

Golte, J. \& León, D. (2011). Polifacéticos. Jóvenes limeños del siglo XXI. Lima: IEP - Atoq Editores.

Gupta, A. \& Ferguson, J. (2008 [1997]). Más allá de la cultura. Espacio, identidad y las politicas de la diferencia. Traducción de Erna von der Walde. Antipoda, $\mathrm{N}^{\circ} 7$, Julio-Diciembre 2008, 233-256. 
Igarza, R. (2009). Burbujas de ocio. Nuevas formas de consumo cultural. Argentina: La crujía Ediciones

INEI: Lima tiene 8 millones 693 mil 387 habitantes En: la Republica. Pe. Lima, 27/01/14 http://archivo.larepublica.pe/17-01-2014/inei-lima-tiene-8-millones-693mil387-habitantes Consultado el 29/06/14

International Society of Metal Music Studies (ISMMS) (2014). En: http://www.ucmo.edu/metalstudies/metal_studies_home.html. Consultado el 17/04/14 Lipovetsky, G. \& Serroy, J. (2009). La pantalla global. Cultura mediática y cine en la era hipermoderna. Barcelona: Editorial Anagrama.

Maldonado, V. et al. (2008). Representaciones sociales hacia una cultura del Metal, de un grupo de Metaleros de Bogotá. Artículo de Tesis publicado en la revista Diversitas. Perspectivas en psicología, vol. 5, núm. 1, pp. 111-124. Bogotá:

Universidad SANTo Tomás (2014). En: http://www.redalyc.org/pdf/679/67916259010.pdf. Consultado el $18 / 04 / 14$

Mejía, J. (2002). Problemas metodológicos de las ciencias sociales en el Perú. Lima: Fondo Editorial de la UNMSM. Facultad de Ciencias Sociales.

Mejía, J. (2014). Sociedad, consumo y ética. El Perú en tiempos de globalización. Lima: Fondo Editorial de la UNMSM. Facultad de Ciencias Sociales.

Monterroso, C. (2006). La defensa de la autenticidad: el placer y la muerte en el discurso del Heavy Metal. En: Anthropia revista de antropología y otras cosas. $\mathrm{N}^{\circ} 4 \mathrm{pp}$. 39-45. Lima: PUCP.
Pérez, M. (2013). la obra de Bourdieu como marco de análisis sociológico del Rock. En: http://musyca.es/la-obra-debourdieu-como-marco-de-analisissociologico-del-rock/. Consultado el 17/04/14

SÁnchez, M. (2007). Thrash Metal: del sonido al contenido, origen y contenido de una contracultura. Tesis de Licenciatura en Sociología. Chile: Universidad de Chile. En: https://www.academia.edu/4005916/Thrash_metal_ del_sonido_al_contenido. Consultado el 18/04/14

Torres, C. (2012). Se acabó el show. 1985, el estallido del rock subterráneo. Lima: Editorial Mutante.

WARNIER (1999). La mundialización de la cultura. Barcelona: Editorial Gedisa, S.A. Yépez, J. (2013) Política cultural neoliberal y la música Heavy Metal en la ciudad de Huánuco, Perú 1990-2010. Artículo de Tesis publicado En: Revista de Investigaciones Sociales, Vol. 17, N030 pp. 279 290. Lima: Universidad Nacional Mayor de San Marcos.

Yrrivaren, S. (2015). El ginius loci del Metal en Lima. En: Romero, R. [Editor] Música popular y sociedad en el Perú contemporáneo. Lima: IDE - PUCP pp. 282-301.

YrRIVARren, S. (2012). Tribus Urbanas en Lima. Jóvenes y Adolescentes en busca de un espacio en la ciudad, 19902010. Lima: Arquitectura de Bolsillo - PUCP.

YúdicE, G. \& Miller, T. (2002a). Política cultural. Barcelona: Editorial Gedisa, S.A.

YúdICE, G. (2002b). El recurso de la cultura. Usos de la cultura en la era global. Barcelona: Editorial Gedisa. S.A. 